\title{
Characterization of Iron Ore via Combining Optical and EBSD Technique
}

\author{
M.C.O. Mendes *, L. Lagoeiro*, G. Alvares ** \\ *Dep. of Geology, Federal University of Ouro Preto, Ouro Preto, MG, 35400-000, Brazil \\ ** Dep. of Metallurgy, Federal University of Ouro Preto, Ouro Preto, MG, 35400-000, Brazil
}

The EBSD plays an important role in the material sciences, concerning with the characterization of microstructural parameters (grain size and axial ratio), crystallographic preferred orientation and phase identification. The application of this technical can be carried out in geological materials, obtaining satisfactory results, for an adequate sample preparation. Hematite/magnetite ores were characterized through this technique, in order to obtain a complete characterization. The samples were collected in different geological context (Fig. 1), in the Quadrilátero Ferrífero region (Minas Supergroup, Cauê Formation [1]) in Minas Gerais state, Brazil, in order to establish the different characteristics of the ores related to the different deformational and metamorphic conditions [2].

Analyses were performed in a scanning electron microscope (SEM) JEOL JSM5510, with a Nordlys HKL-Oxford EBSD detector in the Laboratory of Microscopy and Microanalysis, Dep. of Geology, Federal University of Ouro Preto. Samples were oriented with the X-axis parallel to the lineation and the Z-axis normal to the foliation plane. EBSD data were acquired through the software package Channel 5. The data acquisition, identification of mineral phases and automatic measurement of grain size/shape and grain boundary mapping was made through the Tango module. Pole figures for the basal, prismatic and rhomb planes were obtained through the PFch5 software [3].

The mineral phases maps obtained through the EBSD-were compared with those obtained in the optical microscope by hand contouring the grain boundaries (Fig 2). Despite the good match for the two methods, differences arise due to indexing errors, for example, similar crystallographic systems (quartz and hematite). However, the application of the automatic technique in acquiring grain size distributions and other microstructural parameters needs further studies to test the accuracy of the method. This is particularly important since the difficulties found in determination of hematite grain sizes through optical microscopy. Finally, the orientation maps (Fig 3) and crystallographic orientation data depicted in the pole figures (Fig 4) corresponds to the observations made in the optical microscope. The specimens show strong shape preferred orientations with strong concentrations of the poles of crystallographic planes around the reference sample directions.

It can be concluded that the EBSD technique is a very usefull technique for a complete characterization of iron ores. Although the optical microscopy techniques provide a more complete imaging of the whole microstructures, it lacks the capability of an integration of the microstructural data and the complete crystallographic orientation of the aggregates. Therefore one should consider these two methods as complementary techniques for an ore-mineral characterization.

\section{References:}

J. V. N. 2nd. Dorr, U. S. Geol. Surv. Prof. Pap., 641 - A (1969) 1-110.

C. A. Rosière et. al, Journal of Structural Geology, 23 (8) (2001) 1429-1440.

D. Mainprice, ftp://www.gm.univ-montp2.fr/mainprice//CareWare_Unicef_Programs/, 2007. 


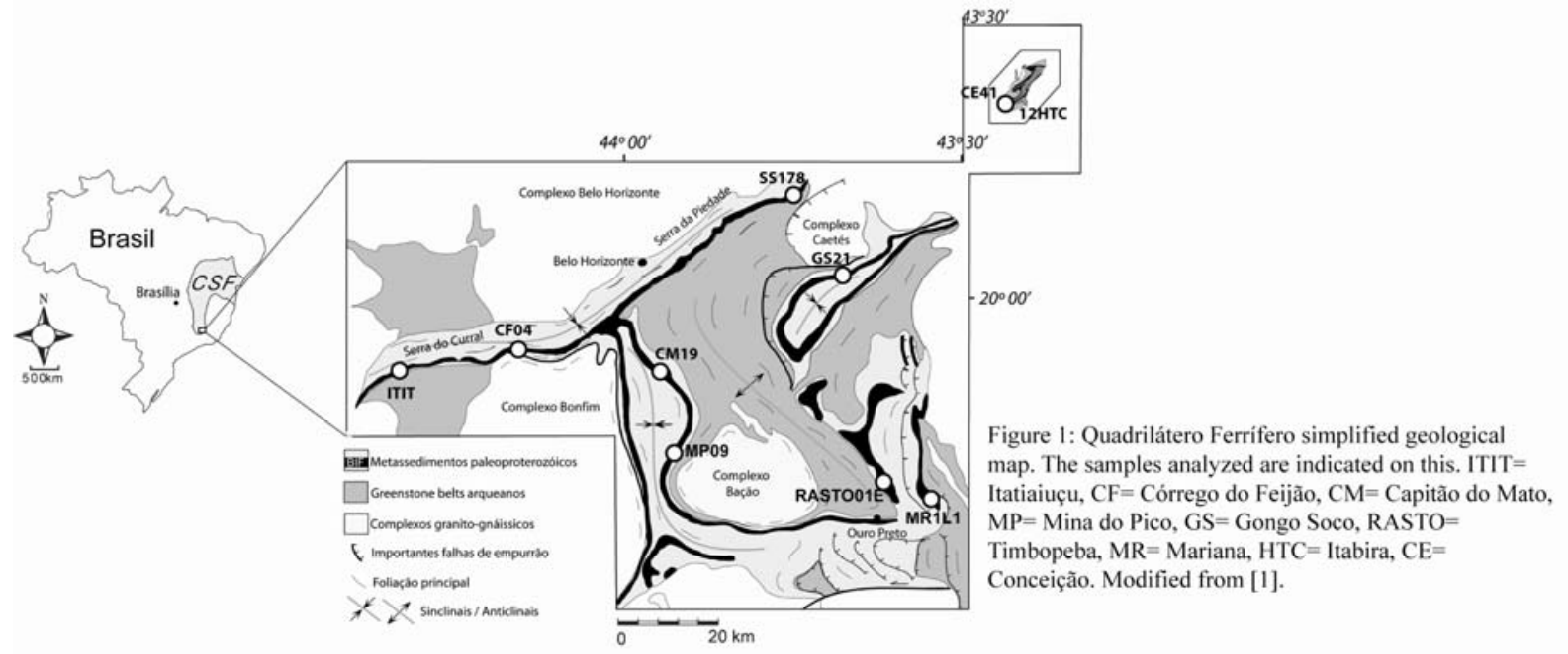

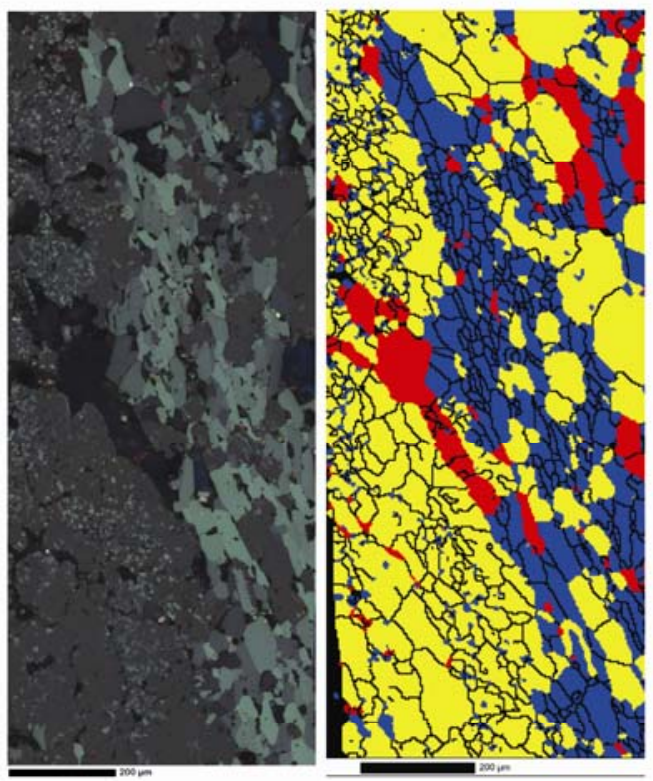

Figure 2: Reflected light microscope photomicrography mosaic and EBSD mineral phase map (magnetite- yellow, hematite- blue and quartz- red) obtained for the sample RASTO-0IE. Comparation shows a good match between the methods (differences due to indexing errors).

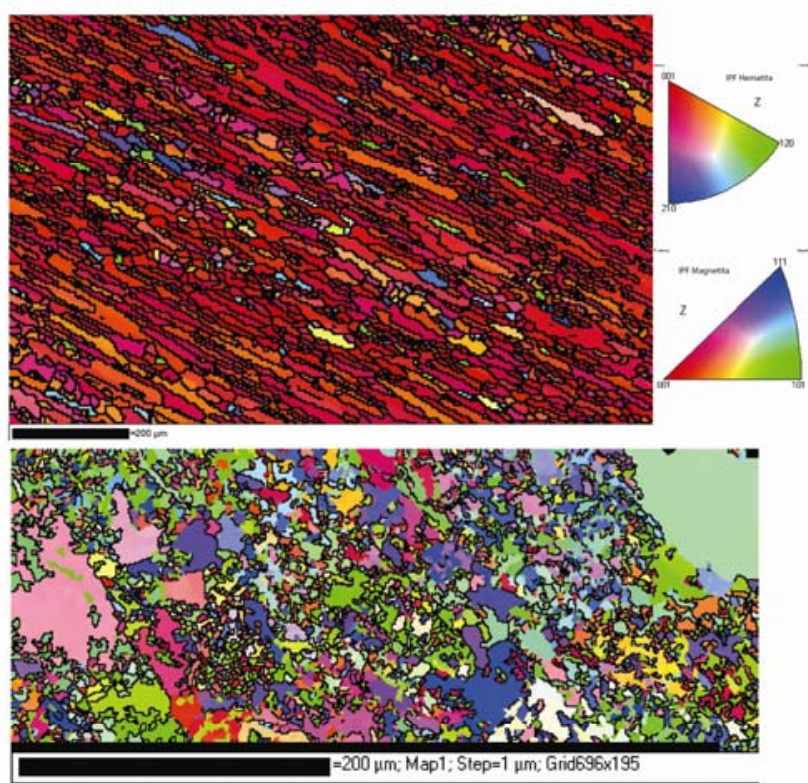

Figure 3: Crystallographic orientation maps obtained from EBSD. The IPF (Inverse Pole Figure) maps shows the crystallographic orientation related to the reference system of the sample. The upper map (12HTC) shows a strong shape preferred orientation, contrasting with the lower map (ITIT). Legend refers to different colors in the map, corresponding to different orientations.

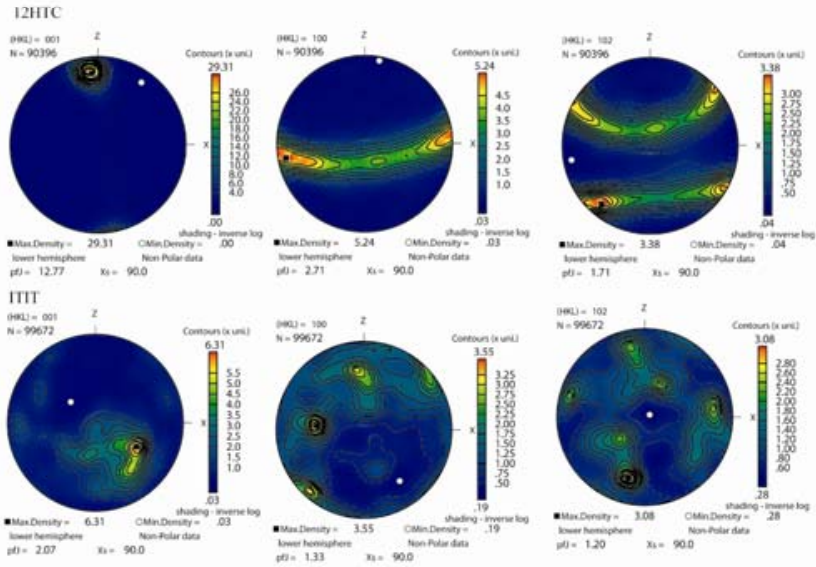

Figure 4: Pole figures obtained from the samples on Fig 3 for basal (001), prismatic (100) and rhomb (102) crystallographic planes, calculated from [3], low hemisphere. It can be observed the strong concentration of the poles of the referred planes in the sample 12HTC, indicating a strong crystal preferred orientation. The other sample (RASTO-01E) shows a very dispersive distribution of the poles. 